\title{
Translating into Textual Genres ${ }^{1}$
}

\section{Isabel García Izquierdo \\ Vicent Montalt i Resurrecció}

Universitat Jaume I

When we translate, we do so for specific communicative situations and purposes; that is, we write translations that will fulfil the needs and conventions of specific textual genres in the target language and culture. The aim of this article, which draws on data and experience from the GENTT project, is to explore the relationship between translation and genre theory in order to understand better how translators are involved in interlinguistic and intercultural communication.

Genre theory is attractive to Translation Studies because it links the micro level of writing and text to the macro level of discourse and context, unites process with product and integrates the cognitive, social and professional approaches to translation. Thus, the notion of genre brings together critical elements in translation such as the reader's profile, expectations and preferences; the communicative situation and purpose; and the socio-cultural context. In order to understand better how translators are involved in interlinguistic and intercultural communication, we suggest a remodelling of translation in which the target genre plays a central role.

\section{Introduction}

Recent developments in Translation Studies show that translating can be defined as an act of communication carried out in particular situations. As such, any translation reflects characteristic features concerning the communicative purpose, the participants in the act of communication, the microstructure (text) and the macrostructure (context). However, translation is a complex act of communication since participants share neither the language nor the culture. The reader's expectations, the interpretation of the communicative purpose as well as macrostructural and microstructural features of a given text pose a challenge for the translator, whose basic task is to mediate between languages and cultures.

Starting from the relationship between translation and genre theory, we intend to shed light on the task of the professional translator in the fields of medicine, technology and law. We suggest that genre is both the starting point and the target of translating. Either consciously or unconsciously we translate from and into genres. This enables us to take into account all relevant communicative factors from the point of view of process and from that of product. Genre is therefore seen as a space where all fundamental elements of the communicative act converge and where the three-fold linguistic, cognitive and cultural (socio-professional) perspectives of translationoriented analysis can be fully developed. 


\section{Genre Theory}

From the 70s and 80 s, genre as a semiotic notion concerning the intercultural nature of translating has become a focus of interest within Translation Studies. Prominent among the authors who have dealt with genre ${ }^{2}$ and translation are Hatim and Mason (1990), who developed their own perspective following work done in audiovisual communication (Kress 1985) and in systemic functionalism (Martin 1985). According to them, genres are 'conventionalised forms of texts' which reflect the functions and goals involved in particular social occasions as well as the purpose of the participants in them.

Therefore genre is viewed as a notion that links together formal ('conventionalized forms'), sociocultural ('social occasions') and cognitive ('purposes of the participants') aspects of communication. This three-fold dimension plays a central role in our understanding of the complexity of genres in different languages and cultures.

In a recent article (García Izquierdo, forthcoming) genre is defined as "the conventionalised form of a text that has a specific function in the culture in which it is embedded and reflects a purpose of the sender which can be readily understood by the receiver". This definition follows closely that provided by Hatim and Mason and establishes a distinction between genre and text type, the latter referring to conventionalised forms of text in relation to linguistic structure, the former to sociocultural use (see Castellà 1995). In other words, genre is a culture-specific category through which it is possible to observe the diverse ways in which different languages conceptualize reality (García Izquierdo 2000).

Similarly, Monzó (2002:82) suggests that looking at genre from a cultural perspective implies considering it as a means of socialization, the translator's task being to produce a new discursive text from the original.

Our hypothesis, then, is that different languages conceptualize reality in different ways according to a set of cultural elements including register, terminological preferences, phraseology or ideology. Therefore, an analysis of such elements in both languages can be useful to detect transcultural conventions prior to translation. In our view, the notion of genre is a platform where all translation-relevant elements converge, hence our decision to use it as the guiding concept in our research.

\section{Distinguishing genres}

As has been pointed out in previous research (García Izquierdo, forthcoming), it is difficult to establish clear-cut borders between different professional genres in different languages. The GENTT project, which aims at creating an electronic encyclopaedia of genres in the fields of medicine, technology and law, faced complex difficulties in establishing an initial list of genres due to the blurred borderlines between genres and subgenres and also between fields. Patents are a good example of the difficulties involved in classifying genres that are used in more than one field. An additional diffi- 
culty was whether to include or exclude transcultural genres, that is, genres that do not vary significantly from language to language and, therefore, do not apparently pose a challenge for the translator.

According to Fowler (1982:42, as cited by Paltridge 1997:33) "A solution may lie in Wittgenstein's (1953) notion of 'family resemblances', arguing that genres may be regarded as 'making up a family' whose steps and individual members are related in various ways, without necessarily having any single feature shared in common by all."

Bhatia (1998:27) asserts that genres have characteristic features that make them dynamic, creative and versatile, and that these features have to do with differences in organization and in the strategies used by participants to achieve their purposes. In his opinion (1998:31), any professional writer of genres "needs to have sensitivity to inter- and cross-cultural constraints operating on genres across national, cultural and ethnic boundaries." Consequently, the translator as a professional writer should be aware of these restrictions.

As far as the problem of establishing the borders between genres is concerned, in our view Monzó's proposal may be useful. According to her (2002:141) genres can be subdivided into the following variants, based on cultural criteria: paragenre, diagenre and idiogenre. A paragenre is a genre belonging to a professional community, whereas a diagenre is a genre restricted to a particular geographical location. Idiogenre refers to a genre that reflects the idiosyncratic features of the author who makes constant use of it.

In addition to these variables, Monzó proposes the notion of transgenre for Translation Studies. A transgenre is a genre restricted to translation, which reflects the three-fold dimension - cultural, cognitive and discursive - and which shows similarities and differences with respect to original texts both in the source and the target texts (Monzó 2002:251).

The notion of transgenre is relevant in specialized translation because it accounts for the lack of apparent homogeneity in some fields and because it allows us to define transgenres in each field regardless of the fact that source and target genres may not share all features.

\section{Genre and corpus methodology}

Consistent with current methodological trends within Translation Studies, the research carried out by GENTT is based on Corpus linguistics and, therefore, uses corpus methodology $y^{3}$. We study language variation across genres, languages and cultures by means of electronic corpora that have been selected and classified according to a set of established criteria, which include, according to Marcos Marín (1994), the retrieval of information on electronic format; the clarity of rules to access information; and standard, transparent codification of texts.

On the basis of the degree of specialization and the size of texts, it is possible to establish a more or less varied typology of genres (see the clas- 
sification proposed by Corpas 2001:3). In general terms, the GENTT corpus can be defined as follows: it allows for comparisons because it includes similar types of texts in different languages; it is specialized since it includes texts from the fields of medicine, technology and law; it is textual in as far as it contains whole texts; it is annotated with linguistic and metalinguistic labels; and it is documented, that is, each document contains a header describing its origin.

\section{Remodelling the translation process}

One of the implications in the use of the GENTT corpus for the research and teaching of medical, technical and legal translation is that the target genre seems to play a key role in specialized translation. As far as professional practice in the fields of medicine, technology and law is concerned, a translation is needed both a) when the participants in a given communicative situation lack a text which is indispensable to achieve their goals and b) when such a text can be obtained from an existing text written in another language.

Let us quickly imagine three communicative situations encountered in the field of medicine by a team of scientists working in a laboratory, by a team of physicians working in a hospital, and by a patient, all of them in a Spanish-speaking country. In the first situation, the scientists lack essential knowledge to carry out their original research and distribute it among the medical community. In the second situation, the physicians need knowledge for professional purposes, for instance for implementing a new technique for the treatment of a particular disease. Finally, when taking a drug prescribed by the physician, a patient needs information about its therapeutic indications, composition, dosage, side effects, expiration, and so on. Here we have three communicative situations that correspond to three textual genres - the original article, the guide to practice and the patient's information leaflet.

In each of them there is a textual gap or niche that will be filled by the translation and the translation needs arise within a given target genre embedded in a professional or a non-professional setting, such as the laboratory, the hospital or the patient's environment in the above-mentioned examples. Put differently, a translation need arises in a communicative situation that has a textual gap or niche which impedes efficient communication within the genre. Such a gap or niche will be occupied by the translation and efficient communication will be restored.

In this process, the source text provides mainly conceptual information (the ideational input) required by the participants in the target communicative situation, whereas rhetorical, cultural and stylistic knowledge (interpersonal and textual input) is provided by the target genre. From this viewpoint, the target genre is seen as a source of accepted habits, restrictions (norms, conventions) and possibilities of communication. In its turn, the source text naturally belongs to a specific genre in the source culture, which does not necessarily coincide with the target one. 
As a reader of the source text, the translator participates in the source genre, his main objective being extracting the information required by the target reader. As a writer, the translator participates in the target genre, his main objective being to produce a text that will eventually be inserted in a particular target situation. The translator will probably feel that non-professional genres, such as the patient's information leaflet, are more familiar to him since he will no doubt have come across them as a 'real' reader. However, in professional genres, the translator can be best described as an outsider in both source and target genres in the sense that he does not belong to the professional community he is translating for.

Being an outsider enables him to focus on the genre as a whole - not just the specialized contents and terminology - and to understand not only its communicative habits, restrictions and possibilities, but also the way in which different genres interact in both the target and the source languages and cultures. Such multilingual and multicultural generic knowledge not only constitutes the translator's expertise and defines his professional identity, it is also crucial for his role as a interlinguistic and intercultural communicator.

A remodelling of the translation process

Text need in a particular
communicative situation (target genre)
motivated by exigencies such as lack of
knowledge, legal requirement, etc.
Source of information (source text
belonging to source genre)
$\downarrow$
Processing the information from source
text (taking into account both the
original and the target genres where the
information was and will be used)
$\downarrow$
Textualizing the information from
source text in target language
according to target genre
$\downarrow$
Using the translation in the target genre
to achieve multiple communicative
goals

This probably constitutes a shift in perspective: moving the main focus from language and culture as abstract entities to actual communication in specific settings, that is, to genre, where language and culture take a backseat to the achievement of communicative goals. Thus, one of the main ideas underlying the GENTT project is that translators are actively involved in genres. 
Hence the GENTT corpus basically provides generic information that can be useful both to process the information and to textualize it in the adequate form of the target genre.

In specialized written communication, the primary question seems to be the knowledge translators have about how professional and non-professional participants interact in specific communicative situations by means of written texts. As we have mentioned, this knowledge is called generic knowledge which is the basis of generic competence. This assumption has important consequences for the pedagogy of specialized translation.

\section{Pedagogy of specialized translation: enhancing generic competence}

There are two basic questions related to the pedagogy of specialized translation: what to teach and how to teach it. The generic approach offers some clues. In as far as the question of "what to teach" is concerned, two issues should be taken into account. On the one hand, some genres are more common than others in interlinguistic and intercultural communication. Among the most frequently translated genres in the fields covered by the GENTT corpus are instruction manuals, catalogues, contracts, patents, technical reports, patient information leaflets and the review articles. On the other hand, some genres are close to the student's communicative experience; e.g. popularising articles, patient information leaflets and instruction manuals, whereas others may be far removed from it; e.g. original articles or industrial product specifications. Consequently, teachers should grade their teaching materials, starting with what is likely to be within the students' experience and gradually moving on to what is less familiar or more specialised.

As to the "how", special emphasis should be placed on two non-linguistic often forgotten matters. First, that the motivation of the translation process is normally a lack of information in the target reader, who is - in one way or another - involved in some professional or non-professional communicative situation, and who will read the translation in order to achieve a given communicative purpose. Second, that the target genre is conceived of as a communicative space in which the written text - that is, the translation - is but one among several key factors. Exploring them in detail may help the student choose strategies and take decisions to solve the difficulties and problems posed by the translation brief. Teachers should not only provide their students with generic information, but should also encourage them to find out more about the source and the target genres they are dealing with. The study of parallel texts used by the target community is a good solution.

In addition to parallel texts, another factor that can enhance generic competence is socializing with active members of the genre, that is, with professionals who work in a specific setting where a particular genre is used. In other words, co-operation with field experts is essential for the training of professional translators, because it is probably one of the best ways to help them gain some insight into the non-linguistic aspects of the target genre, 
such as the actual reader's profile, his/her expectations, the professional purposes to which the text will be put, and the communicative habits of the field.

Therefore, rather than insisting primarily on the change of language and culture, we propose that the pedagogy of specialized translation should put greater emphasis on the fact that translators participate in genres, especially in target genres.

In short, in our view, enhancing generic competence should be one of the main objectives in specialized translation courses. The GENTT encyclopaedia is designed to provide the kind of generic information that specialized translation pedagogy needs, to do so.

\section{Conclusions}

It is often claimed that translation is an interlinguistic and intercultural type of communication. However, the linguistic and cultural approaches to specialized translation do not always provide the kind of framework translators really need in order to understand what their profession actually consists of. On the one hand, the linguistic and cultural approaches tend to be too broad and too vague. Cultures can be interpreted as systems of genres (Martin 2000), but translators do not get involved with "cultures in general", they are confronted with specific genres and systems of genres. On the other, some genres such as that of the original article or the FAQ are becoming increasingly internationalized and less culture-bound in as far as functions and formal conventions are concerned. Finally, linguistic and cultural approaches tend to ignore critical aspects such as the professional practice related to a particular genre and thus fail to focus on what translators actually do, which is enabling readers to carry out their communicative goals in specific situations.

If translating is a communicative act, then the notion of genre is critical to understand the full scope of what translators actually do. Genres are not just semiotic constructs that impose restrictions upon the translator but, put in Bazerman's words (1998), "opportunity spaces for realising certain kinds of activities, meanings and relations". Genres offer multiple communicative resources that must be used to empower the translator, instead of restricting him.

In our opinion, the generic approach focuses on the communicative space in which legal, medical and technical translators carry out their professions. Translations are interlocked with genres, which themselves are "staged goal-oriented social processes" (Martin 2000). From this perspective, more emphasis should be placed on generic knowledge and competence in the training of professional translators. The GENTT encyclopaedia of specialized genres takes the notion of genre as the interface between language and use in specific communicative situations and aims at providing the generic knowledge required to enhance this kind of competence. 


\section{Bibliography}

Bazerman, Charles (1998). "Emerging perspectives on the many dimensions of scientific discourse." J. R. Martin \& Robert Veel (eds) (1998). Reading Science. Critical and Functional Perspectives on Discourse of Science. London/New York: Routledge, 15-28.

Bhatia, Vijay K. (1998). "Generic Conflicts in Academic Discourse.” Imma Fortanet et al. (eds) (1998). Genre Studies for Academic Purposes. Col-lecció Summa Filologia 9. Castelló: Universitat Jaume I, 15-28.

Bhatia, Vijay K. (1999). "Integrating products, processes, purposes and participants in professional writing." Christopher N. Cadlin \& Ken Hyland (eds) (1999). Writing: Texts, Processes and Practices. London/New York: Longman, 21-39.

Berkenkotter, C. \& T. N. Huckin (1995). Genre Knowledge in Disciplinary Communication. Hillsdale/New Jersey: Lawrence Erlbaum Associates Publishers.

Cadlin, Christopher N. \& Ken Hyland (eds) (1999). Writing: Texts, Processes and Practices. London/New York: Longman.

Castellà, J. M. (1995). "Diversitat discursiva i gramàtica. Avantatges i mites de la tipologia textual." Articles de Didàctica de la Llengua i la Literatura 4, 73-84.

Corpas, Gloria (2001). "Compilación de un corpus ad hoc para la enseñanza de la traducción inversa especializada." TRANS 5, 65-74.

Fortanet, Imma et al. (eds) (1998a). Genre Studies for Academic Purposes. Col-lecció Summa Filologia 9. Castelló: Universitat Jaume I.

Fortanet, Imma et al. (1998b). "Disciplinary Variations in the Writing of Research Articles in English." Imma Fortanet et al. (eds) (1998). Genre Studies for Academic Purposes. Col-lecció Summa Filologia 9. Castelló: Universitat Jaume I, 59-78.

García Izquierdo, Isabel (2000). Análisis textual aplicado a la traducción. València: Tirant lo Blanch.

García Izquierdo, Isabel (forthcoming). "El género: plataforma de confluencia de nociones fundamentales en didáctica de la traducción." To appear in Discursos. Estudos sobre traduçao 2.

García Izquierdo, Isabel \& Ester Monzó (forthcoming). "Enciclopèdia electrònica de gèneres: anàlisi i descripció dels gèneres especialitzats i aplicacions a la traducció." To appear in I Jornada de la Xarxa Coneixement i Llenguatge. València: Universitat de València.

García Izquierdo, Isabel \& Ester Monzó (forthcoming). "Enciclopèdia electrònica de gèneres textuals per a la traducció." To appear in La traducció cientificotècnica $i$ la terminologia en la societat de la informació. Col-lecció Estudis sobre la traducció. Castelló: Universitat Jaume I.

Hatim, B. \& I. Mason (1990). Discourse and the translator. London: Longman.

Hurtado Albir, Amparo (2001). Traducción y Traductología. Introducción a la Traductología. Madrid: Cátedra.

Hyland, K. (1999). "Disciplinary discourses: writer stance in research articles." Christopher N. Cadlin \& Ken Hyland (eds) (1999). Writing: Texts, Processes and Practices. London/New York: Longman, 99-121.

Kenny, D. (2001). Lexis and Creativity in Translation. A Corpus-Based Study. Manchester: St. Jerome.

Kress, G. (1985). Linguistic Processes in Sociocultural Practice.Victoria: Deakin University Press.

Malcom, I. G. (1999). "Writing as an intercultural process." Christopher N. Cadlin \& K. Hyland (eds) (1999). Writing: Texts, Processes and Practices. London/ New York: Longman, 122-141. 
Marcos Marin, F. (1994). Informática y Humanidades. Madrid: Gredos.

Martin, J. R. (2000). "Grammar meets genre: reflections on the 'Sydney School'." Arts 22, 47-95.

Montalt i Resurrecció, Vicent (2002). "The concept of textual genre and its relevance in scientific and technical translation." Francisco Fernández (ed.) (2002). Los estudios ingleses. El presente y el futuro de nuestra disciplina. València: Universitat de València, 241-250.

Monzó Nebot, Ester (2002). La professió del traductor jurídic i jurat: descripció sociològica del professional $i$ anàlisi discursiva del transgènere. $\mathrm{PhD}$ thesis. Universitat Jaume I.

Paltridge, B. (1997). Genre, Frames and Writing in Research Settings. Amsterdam/ New York/Philadelphia: John Benjamins.

Todorov, T. (1993). Genres in Discourse. Cambridge: Cambridge University Press.

${ }^{1}$ This research has been carried out within GENTT (Gèneres textuals per a la traducció / Textual Genres for Translation), a project being developed at the Universitat Jaume I (Castelló, Spain), funded by Generalitat Valenciana (GV00-155-09) and Bancaixa-Universitat Jaume I (Pl.1.2000-02).

${ }^{2}$ For a revision of the notion of genre in different fields, see Monzó 2002:94. For a revision of the notion of genre from the point of view of scientific and technical translation, see Montalt 2002.

${ }^{3}$ For a revision of the use of corpus methodology in translation studies, see Kenny 2001:57. 